\title{
EXPECTATIVAS EM TORNO DO CINEMA EM WALTER BENJAMIN E THEODOR ADORNO
}

Emanuelle Beserra de Oliveira ${ }^{1}$

\begin{abstract}
RESUMO
Investigar, na arte pós aurática da reprodutibilidade técnica, o conceito de falsa mimese quanto à produção cinematográfica sob a ótica adorniana em contraponto a observação de uma "explosão terapêutica do inconsciente", na hilaridade coletiva, de acordo com a ótica benjaminiana. Visto que a reprodução técnica da arte colabora para o processo de "desartificação" da mesma (Entkunstung der Kunst), possibilitando na concepção adorniana uma mercantilização da arte, é preciso entender até que ponto as condições de dominação se desviariam da bárbarie cultural para promover, segundo Theodor Adorno uma educação para emancipação e segundo Walter Benjamin, a preparação do aparelho perceptivo para interceptar os choques.
\end{abstract}

Palavras-Chaves: Cinema. Mimese. Inconsciente. Percepção. Reprodutibilidade Técnica.

\section{Cinema's expectations in Walter Benjamin and Theodor Adorno}

\begin{abstract}
This paper intends to investigate in the auratic post art of technical reproducibility the fake concept of mimesis from the viewpoint at the film production according to Adorno's view in contrast of a "therapeutic explosion of the unconscious" and according to Benjamin's perspective the collective hilarity. Since the technical reproduction of art contributes to the process of "des-artification" by itself (Entkunstung der Kunst) enabling the Adornian design one commodification of art has to be understand until at which point the conditions of domination diverts from the cultural barbarism to promote second Theodor Adorno one education for emancipation and according to Walter Benjamin the preparation of the perceptual system to intercept the schocks.
\end{abstract}

Keywords: cinema, mimesis, unconscious, perception, technical reproducibility

\footnotetext{
${ }^{1}$ Emanuelle Beserra de Oliveira é Graduada em Filosofia e Mestranda em Filosofia - UECE.
} 
Segundo Adorno a técnica de reprodução empregada na obra-de-arte abandona qualquer possibilidade de libertação do indivíduo, fim que deveria ter sido alcançado, em um pensamento teleológico, na proposta da ciência absolutizada pela razão. No lugar de emoldurar a consciência esclarecida da Aufklärung,, essa razão jaz instrumentalizada, esquecendo os apelos afetivos e anímicos do homem da Modernidade e a arte aparece, muitas vezes, com um aparato técnico de cunho propagandístico, a serviço da guerra imperialista, isto é, a arte reproduzida auxilia no processo de dominação, deixando clara a regressão da humanidade - em um retorno da cultura à barbárie. Já em O Fetichismo da música e em "Indústria Cultural, Mistificação das massas" de Dialética do Esclarecimento, essa constatação tem unanimidade. Aí Adorno avalia as diferentes nuanças da manipulação da vontade, impedindo o poder geral de escolha e decisão. Nesse caso, em que o processo de hipnose do indivíduo sem vontade, diante do deslumbramento motivado pela técnica fica bem patente, ele deduz o contexto do ofuscamento (Verblendungszusammenhang), que leva o homem, entre outras circunstâncias, às últimas consequências do consumo, represando no objeto de arte a sua paixão pelo palpável (Leidenschaft zum Antasten), como para compensar o vazio afetivo das relações partidas pelo mesmo capital. É quando a crítica de Adorno condena a utilização da reprodução técnica para a pura comercialização. Benjamin ao tratar da técnica não a rejeita. Ao contrário. Produz um sinal de alerta para a maneira de como utilizá-la, evitando a falsa impressão de avanço que, na verdade, conduz ao retrocesso. Em a obra de arte na época de sua reprodutibilidade técnica, Benjamin mostra a saída da arte de uma dimensão para outra, ou seja, vê a passagem do seu estágio de sacralidade, quando ela era contemplada pelo seu valor de culto (Kultwert) para assumir o valor de exposição, (Ausstellungswert). Exilada do plano da devoção, a arte da fotografia e do cinema passam a ser estudadas, e avaliadas como objeto de distração e/ou de contemplação, onde o filósofo judeu de Berlim vê a possiblidade de educar a massa. A reprodução técnica impõe assim formas novas de se produzir e de se apreender a obra-de-arte.

Ao estudar Adorno nos deparamos com severas críticas feitas ao cinema. Ao ler Benjamin percebemos uma flexibilidade maior quanto à sétima arte e ao que esta representa na sociedade. Podemos questionar o por quê dessas posições contrárias de pensadores que desenvolveram suas teorias em momentos tão próximos. Para expor tais indagações a obra Dialética do Esclarecimento de Adorno e Horkheimer, 
em particular o texto Indústria cultural: o esclarecimento como mistificação das massas, dedicado à análise da indústria cultural, será colocado frente ao ensaio benjaminiano "A obra de arte na época de sua reprodutibilidade técnica", no qual o modo de produção artística tem sido veiculado preponderantemente ao aparecimento da fotografia e do cinema.

Devemos levar em consideração o ano de produção dos referidos textos no sentido de compreender em que momento histórico os autores desenvolveram suas posições acerca do cinema. Adorno escreve a Dialética do esclarecimento em 1944, no momento de seu exílio nos Estados Unidos, motivo pelo qual percebemos uma forte reação contra o cinema hollywoodiano. Benjamin trabalha em sua obra entre 1935 e 1936. Diferentemente de Adorno, Benjamin não presenciou de perto o poder dos grandes estúdios, por vir a falecer em 1940.

Benjamin se mostra entusiasmado com as produções de cineastas como Eisenstein ${ }^{2}$. Pensando na mesma linha de Eisenstein, defende o cinema como arte, acreditando que essa arte poderia expressar os perigos existenciais, com os quais o homem contemporâneo se defrontava na Metrópole moderna, incluindo sua fantasmagoria. Discordando de Benjamin, Adorno acredita que "quanto mais um filme pretende ser arte, tanto mais inautêntico ele se torna”, diz em Minima Moralia (1993, p. 178), A reprodutibilidade técnica que Benjamin mostra em sua obra, não é nada mais e nada menos que a inserção do processo industrial na produção artística. Novas técnicas são desenvolvidas, abrindo espaço para novos processos de produção e reprodução artísticas. Benjamin mostra em seu texto exemplos da evolução da reprodução, citando a escrita, a xilogravura, a litografia, a fotografia que acabam por divulgar e fazer circular de forma mais acessível as obras de arte.

A preocupação que se deve ter com a entrada do processo industrial na arte diz respeito à perda de autenticidade, ou seja, do caráter original da obra. Nessa linha Benjamin desenvolve seu pensamento sobre a aura, ou seja, aquilo que conserva a unidade da obra.

Pode-se resumir essas marcas distintivas com o conceito de aura e dizer: o que desaparece na época da reprodutibilidade técnica da obra de arte é sua aura. Esse processo é sintomático; seu significado vai muito além da esfera da arte. $^{3}$

\footnotetext{
${ }^{2}$ Um importante cineasta soviético que vivenciou a Revolução Russa de 1917 e contribuiu para a consolidação do cinema como expressão artística.

3 BENJAMIN. "A obra de arte na época de sua reprodutibilidade técnica". 2012, p. 23.
} 
Contudo a perda da aura não é vista de forma negativa por Benjamin. Com o fim do valor aurático, a obra-de-arte amplia os horizontes, cria expectativas de relacionamentos no mundo de imagens. Quando a obra se torna independente do contexto histórico em que está inserida, seu teor factual (Sachgehalt) surge seu conteúdo de verdade (Wahrheitsgehalt) e quando se libera das relações de culto (Kultwert), adquire significação no hoje. Ao se libertarem da tradição, as obras-dearte passam a ser expostas através da reprodução técnica, tornando-se apropriação do coletivo, o que permite um maior acesso a todo o público.

Ao falar de cinema Benjamin nos diz que temos uma forma de arte, cujo caráter, pela primeira vez, é determinado de parte a parte por sua reprodutibilidade, ou seja, cinema e reprodutibilidade técnica estão intimamente ligados, pois desde a sua produção e principalmente na sua reprodução a técnica se sobressai.

Benjamin mostra que o filme como arte se desenvolve no momento de sua montagem, assim o cinema é a obra de arte que busca a perfeição. E exemplifica: "para realizar seu Casamento ou Luxo?, que tem um comprimento de 3.000 metros, Chaplin filmou 125.000 metros. Portanto, o cinema é a obra de arte mais perfectível"s.

Ao repensar o cinema como arte, Benjamin, o analisa junto com a fotografia para comparar o caráter artístico da produção cinematográfica:

\begin{abstract}
Um tipo de reprodução é a da fotografia de uma pintura, outro tipo é aquela que se deixa fazer de um acontecimento fictício em um estúdio cinematográfico. No primeiro caso, o objeto reproduzido é uma obra de arte, e a sua produção não o é. Pois o desempenho do fotógrafo com a objetiva cria tão pouco uma obra de arte como o de um regente diante de uma orquestra; no melhor dos casos, cria um desempenho artístico. Outra coisa ocorre no estúdio cinematográfico. Aqui, o objeto reproduzido não é uma obra de arte e a reprodução, por sua vez, tampouco o é, como no primeiro caso. A obra de arte surge aqui somente em razão da montagem. De uma montagem, na qual cada componente individual é a reprodução de um acontecimento, que não é em si mesmo uma obra de arte, nem resulta em uma obra de arte pela fotografia."
\end{abstract}

O cinema resulta na arte da montagem, onde o aparelho impregna tão intimamente no real que aparece como realidade pura. Apesar de toda técnica, onde uma câmera captura as imagens e outras câmeras as montam percebemos 0 equilíbrio entre homem e aparelho, que vem a ser uma das funções sociais que cabe

\footnotetext{
4 Idem. p: 51.

5 Idem, p. 61.
} 
ao cinema compreendido na visão benjaminiana. As imagens na grande tela provocam efeitos na nossa percepção dos atos e gestos diários. E é a perfeição da montagem que nos condicionará a imergir e emergir guiando-nos para experiências em nosso inconsciente, uma vez que "os filmes grotescos americanos e os filmes de Disney provocam uma explosão terapêutica do inconsciente" ${ }^{6}$. Com o avanço tecnológico o cinema permite que seus espectadores possam vivenciar imagens frenéticas e fragmentadas, que exercem um papel terapêutico e didático sobre seus espectadores. Os desenhos animados e filmes grotescos podem oferecer a liberação de uma agressividade em sua forma imaginária, como efeito de sublimação. Percebemos nesse ponto a sintonia do pensamento de Freud com a Teoria Crítica: assim como a psicanálise revelou o inconsciente pulsional, a experiência com o cinema revela um inconsciente ótico, ou seja, aquilo que despertará o público através da sua relação com as imagens do filme.

Para Benjamin, o cinema "serve para exercitar o homem naquelas apercepções e reações condicionadas pelo trato com um aparato, cujo papel em sua vida cresce quase diariamente"7. Porém Benjamin, por possuir uma filosofia de alerta do que se apresenta como agente modificador das relações humanas, nos deixa atentos para a distração e o entretenimento negativo que o cinema possa nos proporcionar, formando hábitos automatizados, denunciando pois a propriedade que a arte possui e retém para mobilizar as massas, por seu alto poder de distração. Para Benjamin o cinema faz a recepção através da distração: a "massa procuraria a distração, enquanto que o amante da arte se aproximaria desta com recolhimento. Para as massas, a obra- de- arte seria uma oportunidade de entretenimento; para o

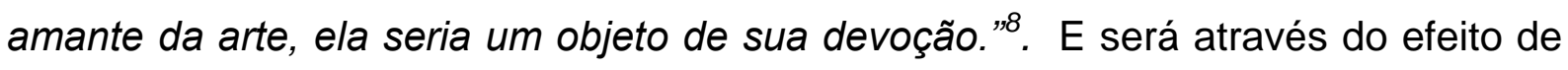
choque, que o cinema causa, que este vem ao encontro dessa forma de recepção.

É nítida a forma de percepção otimista de Benjamin no decorrer da leitura de "A obra de arte na época de sua reprodutibilidade técnica", onde há uma valorização da massa e do processo de reprodutibilidade, como uma forma da arte alcançar a um público maior. Adorno, por sua vez, é considerado muitas vezes elitista e determinista devido ao seu posicionamento quanto à era da reprodutibilidade e de

\footnotetext{
Idem, p. 103.

Idem, p. 45.

Idem, p. 110 e 111.
} 
seus produtos culturais. Porém, o que Adorno nos aponta através de sua severa crítica ao cinema e aos bens culturais, é o retorno da boa arte para todos.

Observando que "o cinema e a rádio não precisam mais se apresentar como arte" $^{9}$, Theodor Adorno, no seu texto 'Indústria Cultural' dá início a um posicionamento quanto á regressão que essa indústria provocou na arte. "Os mass media fabricam industrialmente elementos culturais, segundo as normas do rendimento, da estandartização e da divisão do trabalho, idênticas às do capitalismo."

Usados como meios de difusão e disseminação dos seus produtos impregnados de ideologia, a rádio, as revistas, o cinema e a televisão servem como apoio e força motriz ao desenvolvimento de uma sociedade totalmente administrada (verwaltete Gesellschaft). Os meios de comunicação de massa nos prometem, através da publicidade e da propaganda, colocar a felicidade imediatamente em nossas mãos, por meio da compra de alguma mercadoria: seja ela um CD, um calçado, uma roupa, um comportamento, um carro, uma bebida, um estilo etc. $A$ mídia nos promete e nos oferece essa felicidade em instantes. O público, sob o efeito de uma espécie de hipnose (Verblendungszusammenhang) procura avidamente satisfazer seus desejos. Uma vez que nos tornamos passivos, acríticos, deixamos de distinguir a ficção da realidade, regredimos e, por isso, nos julgamos incapazes e incompetentes para decidirmos sobre nossas próprias vidas.

Uma vez que não nos julgamos preparados para pensar, e desejamos ouvir dos especialistas da mídia o que devemos fazer, nos sentimos intimidados e intimados a aceitar todos os produtos (em formas de publicidade e propaganda) que a mídia impõe. Sem dúvida "os produtos da indústria cultural podem ter a certeza de que até mesmo os distraídos vão consumi-los alertamente”. (ADORNO, 1985)

Com as novas técnicas de reprodução das obras-de-arte, os objetos de arte ${ }^{11}$, perderam o sentido de autenticidade, contemplação e de testemunho histórico.

Adorno ao elaborar esse juízo sobre a não mais representação dessas artes como uma não arte, vivenciava uma época em que a rádio era bastante influente, em que o cinema surgia como uma visão ampla da sociedade projetada num telão. Contudo, hoje a rádio cedeu espaço para a televisão que invadiu as casas das

\footnotetext{
9 ADORNO, e HORKHEIMER. Dialética do Esclarecimento. 1985, p. 238.

10 JIMENEZ.. Para ler Adorno. Tradução de Roberto Ventura. Rio de Janeiro, F. Alves, 1977, p 85.

11 Entenda-se aqui os pertencentes à cultura popular ou à cultura de elite.
} 
pessoas e por mais que o indivíduo fique sentado a sua frente com um controle remoto em sua mão é ela, a televisão, que controla e orienta o que o espectador deverá fazer.

\begin{abstract}
Adorno observa que a estratégia de duplicação do mundo sensível, já presente no filme sonoro, é ampliada na televisão pelo fato de que ela tem mais possibilidade de se imiscuir na vida privada das pessoas, já que seus sinais imagéticos e sonoros as flagram na intimidade de seu lar. ${ }^{12}$
\end{abstract}

Hoje essa invasão é mais acentuada, não basta possuir uma televisão em casa, o objetivo das pessoas é possuírem 2 ou mais espalhadas por toda a casa trazendo para o interior desta o mundo do cinema em pequenas projeções, o que hoje a indústria já tratou de solucionar, proporcionando ao consumidor telas cada vez maiores que se assemelham ao cinema em uma sala de projeção. Mas isso é só mais um projeto de dominação que a indústria oferece, pois quanto mais próximo e mais dentro da sua vida aquela imagem se projete, mais perto dos espectadores estarão os produtos e mais induzidos os modelos perfeitos criados pela indústria cultural. A televisão, portanto, é um meio da cultura de massa que invade a privacidade do indivíduo com o seu consentimento.

Esses vários meios de expressão social para difusão de informações: a imprensa, a televisão, a rádio e o cinema, são orientados para um público que se pretende o mais abrangente possível. Este "ingere" um produto específico de mensagens impregnadas de conteúdo político e ideológico. Nota-se que "nessa medida a pretensão da arte é sempre ao mesmo tempo ideologia", ${ }^{13}$ e estará sempre procurando um meio de propagar a ideologia que se pretende ascender.

Mas, sem dúvida, dentre todos esses meios de vinculação das informações, o cinema foi, para Adorno, e ainda é para nós um objeto de real manipulação que perdeu a característica de arte, pois, quando inserido na moldura da indústria cultural não visava outra coisa, senão o lucro para seus investidores, consequência disso é o impedimento da capacidade do livre pensar do indivíduo. Existe pois toda uma racionalidade técnica, uma razão instrumentalizada para preparar a mente da massa. Resta apenas escolher as opções apresentadas aos nossos olhos, sem muitos questionamentos.

\footnotetext{
${ }^{12}$ DUARTE.. Teoria Crítica da Indústria Cultural. 2003. p. 122.

${ }^{13}$ ADORNO e HORKHEIMER. Dialética do Esclarecimento. 1985. p. 108.
} 
O cinema é um dos maiores objetos da indústria cultural, devido, não só os grandes estúdios produzirem e comercializarem seus filmes, dentro da concepção de uma mass midia poderosa vende muito mais que um produto. Vende-se um estilo de vida, um jeito de ser, um modo de se vestir, portar-se e principalmente os produtos que devemos possuir se quisermos ser mais felizes.

O culto dos astros do cinema tem como complemento da celebridade o mecanismo social que nivela tudo o que chama a atenção. Os astros são apenas os moldes para uma indústria de confecção de dimensões mundiais e para a tesoura da justiça legal e econômica, com a qual se eliminam as últimas pontas dos fios de linha. ${ }^{14}$

Desse modo, o indivíduo se torna um refém da indústria. Acatando e realizando todas as vontades que the são impostas e não as que ele verdadeiramente possui, a indústria cultural diminui seu poder de decisão e seu potencial crítico.

Adorno nos explica bem este fato, ao falar dos filmes, pois muitas vezes somos impedidos de usar de nossa imaginação, de criar nossas próprias ideias relativas ao desenrolar do filme. Os filmes paralisam essa capacidade em benefício do que eles acham que seja mais objetivo e prático para as pessoas. Assim impedem o cultivo de opiniões próprias, deixando que nossos valores sejam regidos por esta máquina que produz pontos de vista lucrativos para os dominadores. Nossos sentidos e sentimentos seriam entregues nas mãos da indústria e seriam manipuladas ideologicamente não fosse o estudo que Benjamin faz da realidade do choque (Chockerlebnis) que prepara a percepção e aguça os sentidos para o alerta diante dos perigos da metrópole moderna.

Os filmes são considerados os principais produtos da indústria, pois eles adestram o espectador, paralisam a capacidade de imaginação em virtude de sua própria constituição objetiva. Visto que:

São feitos de al forma que sua apreensão adequada exige, é verdade, presteza, dom de observação, conhecimentos específicos, mas também de tal sorte que proíbem a atividade intelectual do espectador, se ele não quiser perder os fatos que desfilam velozmente diante de seus olhos. ${ }^{15}$

O espectador traz o filme para a sua realidade, ao passo que se projeta no enredo que acaba de assistir. E quanto melhor a técnica utilizada para a produção

\footnotetext{
${ }^{14}$ ADORNO e HORKHEIMER. Dialética do Esclarecimento. 1985, p. 194.

${ }^{15}$ Idem, p. 104 e 105.
} 
do filme, maior é o poder de persuasão para que se torne mais fácil "obter a ilusão de que o mundo exterior é o prolongamento sem ruptura do mundo que se descobre no filme". ${ }^{16} \mathrm{O}$ cinema propicia uma relação de reconhecimento, a partir do enredo que retrata o cotidiano, deste modo, o processo de identificação acentua a relação mimética ${ }^{17}$ do sujeito com a imagem. Daí percebe-se um dos objetivos da indústria cultural, fazer com que o indivíduo crie a ilusão de que ele é capaz de ser e possuir o que quiser, pois, a imagem cinematográfica, mistura de técnica e sonho, trouxe para o cotidiano das pessoas a possibilidade de materialização do imaginário.

\section{Palavras Finais}

Enquanto Benjamin ao falar da reprodutibilidade técnica desenvolveu uma percepção positiva, quanto ao uso das tecnologias, Adorno aponta as deficiências deste processo. É nesse contexto de oposições que percebemos como certas experiências e vivências foram necessárias se fizeram presente na elaboração das teorias dos filósofos em questão. Importante salientar que nenhum dos dois filósofos elaboraram um trabalho minucioso acerca do cinema, o que fizeram foi nos alertar, através de alguns escritos, para o poder que a sétima arte possui na sociedade. Existem lacunas no pensamento dos dois filósofos que podem ser preenchidas com a interpretação e devem, acima de tudo, Não se pode de um lado defender que o cinema não possua poder revolucionário, pelo fato de estar envolvido no processo capitalista, o que poderia ser avaliado apenas como mais um elemento para a reprodução cultural. Como também não podemos afirmar que é a massa a detentora do controle sobre o cinema, mais precisamente sobre o ator cinematográfico, como defende Benjamin em uma de suas teses. O que podemos fazer é captar cada fragmento desses pensamentos e tentar trilhar um caminho de reflexões esclarecedoras acerca do fenômeno do cinema.

\footnotetext{
${ }^{16}$ Idem, p. 104.

17 Adorno nos mostrará que essa relação mimética, hoje se constitui numa falsa mimese.
} 


\section{REFERÊNCIAS}

ADORNO, T. W. Minima Moralia: reflexões sobre a vida danificada. São Paulo: Ática, 1993

\& HORKHEIMER, M. Dialética do esclarecimento: fragmentos filosóficos. Tradução, Guido Antonio de Almeida. Rio de Janeiro: Jorge Zahar, 1985.

BENJAMIN, W. A obra de arte na época de sua reprodutibilidade técnica. Porto Alegre: Zouk, 2012.

DUARTE, Rodrigo. Teoria crítica da indústria cultural. Belo Horizonte: Editora UFMG, 2003.

JIMENEZ, Marc. Para ler Adorno. Tradução Roberto Ventura. Rio de Janeiro, F. Alves, 1977. 